\title{
EFEITOS DA RADIAÇÃO GAMA NA QUALIDADE NUTRICIONAL DE GRÃOS DE SOJA Glycine max (L.)
}

TAÍS CAROLINA FRANQUEIRA DE TOLEDO SARTORI* SOLANGE GUIDOLIN CANNIATTI BRAZACA** MÔNICA ALESSANDRA TEIXEIRA DOS SANTOS***

VALTER ARTHUR ${ }^{* * * *}$

\begin{abstract}
O presente trabalho teve como objetivo a determinação de alterações consequentes da aplicação de raios gama (doses de 0, 2, 4 e 8 kGy) em dois diferentes cultivares de soja (BRS 213 e Embrapa 48) mediante análises químicas de perfil lipídico, isoflavonas e polifenois totais, livres e ligados a proteínas. Os dois cultivares apresentaram perfil lipídico semelhante e a irradiação promoveu redução nas quantidades de ácidos linolênico e linoleico. Com relação às isoflavonas, o tratamento de radiação promoveu aumento na quantidade das glicosiladas com dose de $2 \mathrm{kGy} e$ diminuição com doses de 4 e 8 kGy. A irradiação também foi responsável pelo aumento da capacidade antioxidante e redução da complexação entre os polifenois e as proteínas. A partir desses resultados foi possível concluir que a radiação gama não alterou significativamente as características químicas dos cultivares de soja estudados.
\end{abstract}

* Doutora em Energia Nuclear na Agricultura, Professora, Departamento de Agroindústria, Instituto Federal de Educação Ciência e Tecnologia do Sul de Minas, Campus Muzambinho, Muzambinho, MG (e-mail: tais.toledo@eafmuz.gov.br).

** Doutora em Ciência dos Alimentos, Professora Associada 2, Departamento de Agroindústria, Alimentos e Nutrição, Escola Superior de Agricultura "Luiz de Queiroz", Universidade de São Paulo (USP), Piracicaba, SP (e-mail: sgcbraza@usp.br).

*** Doutora em Ciência de Alimentos, Universidade Estadual de Campinas, Campinas, SP (e-mail: monica_ alessandra@yahoo.com.br).

**** Doutor em Entomologia, Professor Associado 3, Centro de Energia Nuclear na Agricultura, USP, Piracicaba, SP (e-mail: arthur@cena.usp.br). 


\section{INTRODUÇÃO}

A soja, leguminosa de grande destaque na alimentação humana e animal, constitui importante fonte de proteínas de baixo custo e também de óleo, podendo ser consumida na forma de grãos ou farinha (KAUR e SINGH, 2007).

A soja representa um dos principais itens da produção agrícola brasileira. Em 2011, foram movimentados cerca de 24 bilhões de dólares apenas nas exportações de soja, farelo e óleo (ABIOVE, 2013).

O quinto levantamento de safras de soja, divulgado pela CONAB em fevereiro de 2013, aponta produção de $83.424,3$ mil toneladas em 27.645,9 mil hectares de área plantada (CONAB, 2013), o que mantém o Brasil como o segundo maior produtor mundial de soja, atrás apenas dos Estados Unidos da América.

A manutenção da qualidade dos grãos de soja após a colheita depende de condições ambientais como, local, umidade, temperatura e tempo de estocagem. Muitas perdas ocorrem, principalmente, devido ao ataque de insetos e roedores que provocam alterações nas características físico-químicas do grão e por transformações estruturais de seus componentes, resultando em produto com elevada resistência à cocção e modificações nas suas propriedades organolépticas e nutricionais.

Segundo a EMBRAPA (2012), estimam-se perdas pós-colheita de mais de $10 \%$ dos grãos, sendo a armazenagem o maior problema devido aos prejuízos decorrentes de pragas, fungos e micotoxinas. Durante a armazenagem também se observa escurecimento da superfície do grão, aumento do tempo de hidratação, redução do teor de sólidos e solubilidade proteica, decréscimo no conteúdo de fitatos, conversão estrutural das isoflavonas e oxidação de lipídios (CAl e CHANG, 1999; HOU e CHANG, 2003; 2004). Nessas condições, o grão perde qualidade e reduz seu valor nutricional, podendo causar graves efeitos sobre a saúde humana e animal quando há contaminação por micotoxinas (EMBRAPA, 2012).

A irradiação dos grãos representa alternativa atrativa e saudável na eliminação ou redução da proliferação de micro-organismos, parasitas e pragas, quando comparada aos tratamentos químicos com potencial contaminante.

A aplicação de radiação ionizante, com o propósito de preservar e desinfestar os grãos, constitui pratica promissora utilizada para estender a vida útil dos produtos e diminuir as perdas durante seu armazenamento. Ainda, a irradiação reduz as perdas naturais causadas por processos fisiológicos de brotamento, maturação e senescência. O processo de irradiação acarreta alterações químicas mínimas nos alimentos, nenhumas das quais nocivas ou perigosas, motivo pelo qual a Organização Mundial de Saúde recomenda sua aplicação e uso (DIEHL, 2002; NOVELLI et al., 2008).

Devido à importância da soja e com o intuito de aumentar a sua conservação no período de armazenamento, este trabalho teve por objetivo irradiar dois cultivares de grãos de soja e analisar as possíveis alterações nutricionais promovidas por diferentes doses de irradiação $(2,4 \mathrm{e}$ 8 kGy).

\section{MATERIAL E MÉTODOS}

Desenvolveu-se o experimento no Laboratório de Bromatologia do Departamento de Agroindústria, Alimentos e Nutrição da Escola Superior de Agricultura Luiz de Queiroz (ESALQ), em Piracicaba (SP), sendo os grãos irradiados no Instituto de Pesquisas Energéticas e Nucleares (IPEN) em São Paulo (SP).

Os cultivares utilizados no presente trabalho, BRS 213 e Embrapa 48 (ambos recomendados para o consumo humano) foram doados pela EMBRAPA Soja, Londrina (PR). 


\subsection{PREPARO DAS AMOSTRAS}

Os grãos crus foram tratados com raios gama, nas doses de 0, 2, 4 e 8 kGy, originados de irradiador de Cobalto $^{60}$ (Irradiador Comercial Multipropósito, tipo compacto, com taxa de dose de $12 \mathrm{kGy} / \mathrm{hora}$ ). As doses efetivamente recebidas pelo material, medidas em dosímetro Amber Batch: P., espectrofotômetro Genesis - 20, lidas a $603 \mathrm{~nm}$ e temperatura de $35^{\circ} \mathrm{C}$ foram de: 2,09 a 3,02 nas amostras irradiadas com 2 kGy, de 3,50 a 5,08 nas irradiadas com 4 kGy e de 7,04 a 9,12 para as irradiadas com $8 \mathrm{kGy}$.

As amostras de grãos cozidos, destinadas à realização das análises químicas, foram maceradas por 10 horas em água destilada na proporção 1:3. Desprezou-se essa água e adicionouse água destilada na proporção 1:2. As amostras, cozidas em autoclave a $121^{\circ} \mathrm{C}$ por 10 minutos, foram colocadas em bandejas de alumínio, congeladas e liofilizadas em liofilizador com capacidade de $5 \mathrm{~kg}$ de gelo (marca Modulyo).

\subsection{MÉTODOS ANALÍTICOS}

\subsubsection{Perfil de ácidos graxos}

Para a determinação dos diferentes ácidos graxos efetuou-se a extração dos lipídeos a frio pelo método Bligh e Dyer (1959). As amostras, inicialmente saponificadas com hidróxido de sódio e metanol 0,5 M, foram metiladas com solução de cloreto de amônia, metanol e ácido sulfúrico, segundo Hartman e Lago (1973). Após adição de $5 \mathrm{~mL}$ de hexano, as amostra foram submetidas à agitação por 10 segundos. Retirou-se alíquota de $3 \mathrm{~mL}$ do sobrenadante, que foi ressuspendida em $100 \mathrm{~mL}$ de hexano para injeção no cromatógrafo à gás.

As amostras foram analisadas por cromatografia à gás em cromatógrafo HP 5890 Series II, equipado com detector por ionização em chama, injetor Split e coluna capilar DB-23 de sílica fundida de $60 \mathrm{~m}$ de comprimento e $0,25 \mathrm{~mm}$ de diâmetro interno. Utilizou-se hélio como gás de arraste em fluxo de $1,5 \mathrm{~mL} /$ minuto. As condições cromatográficas foram: temperatura do detector de $280^{\circ} \mathrm{C}$, temperatura do injetor de $270{ }^{\circ} \mathrm{C}$, temperatura inicial da coluna de $130{ }^{\circ} \mathrm{C}$ (durante 1 minuto), temperatura final da coluna de $230^{\circ} \mathrm{C}$ (durante 3 minutos), velocidade de aquecimento $2,75^{\circ} \mathrm{C} / \mathrm{min}$ até $215^{\circ} \mathrm{C}$ (permanecendo nessa temperatura por 12 minutos) e de $40^{\circ} \mathrm{C} / \mathrm{min}$ até atingir a temperatura final.

Os diferentes ácidos graxos foram identificados com base no trabalho de Ratnayake et al. (1990) e da utilização de padrões Sigma. Realizou-se a quantificação dos ácidos graxos por normalização, sendo as porcentagens de área transformadas em concentrações de mg $100 \mathrm{~g}^{-1} \mathrm{de}$ extrato etéreo.

\subsubsection{Extração e determinação das isoflavonas}

\subsubsection{Extração das isoflavonas}

Adotou-se o método descrito por Fukutake et al. (1996) para a extração das isoflavonas. Os grãos de soja foram triturados, peneirados e desengordurados com $50 \mathrm{~mL}$ de hexano por 30 minutos a $25^{\circ} \mathrm{C}$. Centrifugou-se a suspensão e secou-se o resíduo à temperatura ambiente.

As amostras de $1 \mathrm{~g}$ da farinha desengordurada de soja foram submetidas à extração com solução de metanol $80 \%$ (10 mL por 2 horas a $\left.25^{\circ} \mathrm{C}\right)$. Em seguida, foram centrifugadas e o sobrenadante utilizado para análise de isoflavonas por cromatografia a líquido de alta eficiência em fase reversa (CLAE-FR).

Usaram-se padrões de isoflavonas (daidzina, daidzeína, genistina, genisteína, glicitina e 
gliciteína - SIGMA) para identificação, mediante espectro de absorção e quantificação dos compostos na soja, sendo os resultados expressos em $\mu \mathrm{g}$ de isoflavona $/ \mathrm{g}^{-1}$ de soja.

\subsubsection{Determinação das isoflavonas}

As análises dos extratos metanólicos de soja, realizadas por CLAE-FR, seguiram o procedimento descrito por Esaki et al. (1999). Foram injetados $30 \mu \mathrm{L}$ dos extratos em cromatógrafo a líquido, equipado com arranjo de fotodiodos (SPD-M10 AVP, Shimadzu CO.) e coluna C18 SHIMADZU - $5 \mu \mathrm{m}, 4,6 \mathrm{~mm}$.

As condições cromatográficas foram: temperatura da coluna de $30{ }^{\circ} \mathrm{C}$ e fluxo de $0,5 \mathrm{~mL} /$ min. Usou-se como fase móvel (solvente A) a mistura água:ácido acético (19:1) e metanol como solvente B. Iniciou-se o gradiente com $20 \%$ do solvente B, depois $40 \%$ em 15 min e $50 \%$ entre 15 e $55 \mathrm{~min}$, atingindo $80 \%$ em $95 \mathrm{~min}$ e decrescendo para $20 \%$ entre 95 e $105 \mathrm{~min}$. Reequilibrouse a coluna com $20 \%$ do solvente B por 15 min entre as corridas. As isoflavonas eluídas foram detectadas por absorbância a $254 \mathrm{~nm}$.

As concentrações de daidzina, genistina, daidzeína e genisteína foram calculadas por suas curvas-padrão e glicitina e seus conjugados pela curva padrão de daidzina (BARNES, KIRK e COWARD, 1994; COWARD et al., 1998).

\subsubsection{Determinação da atividade antioxidante}

Avaliou-se a capacidade antioxidante dos extratos de soja por meio de dois métodos espectrofotométricos diferentes: sequestro dos radicais livres do DPPH e ABTS. As metodologias para a determinação da capacidade antioxidante são numerosas e podem estar sujeitas a interferências. Assim, nenhum ensaio usado isoladamente pode refletir a capacidade antioxidante total de determinada amostra (HUANG, OU e PRIOR, 2005; PRIOR, WU e SCHAICH, 2005).

\subsubsection{DPPH (2,2-difenil-1-picrilhidrazila)}

Mediu-se a capacidade antioxidante dos extratos dos diferentes cultivares de soja segundo o método proposto por Brand-Williams, Cuvier e Berset (1995), utilizando 1,1-difenil-2-picrilhidrazil (DPPH). A atividade antioxidante foi expressa pela fórmula: \% Atividade antioxidante $=($ Abs do controle - Abs da amostra) ${ }^{\star} 100 /$ Abs do controle. Mediu-se a absorbância a $517 \mathrm{~nm}$ (SINGH, MURTH e JAYAPRAKASHA, 2002).

O método do DPPH baseia-se na reação entre o antioxidante com o reagente DPPH (1,1-difenil-2-picrilhidrazil) que se converte em sua forma reduzida (1,1-difenil-2-picrilhidrazina). Nessa reação, a solução metanólica de DPPH, inicialmente de coloração violeta, torna-se amarelada e o grau de descoloração indica a habilidade do antioxidante em sequestrar o radical livre (ABDILLE et al., 2005). Ocorre a redução do radical mediante abstração do hidrogênio pelo antioxidante, ou seja, avalia-se a habilidade do antioxidante em doar hidrogênio.

Preparou-se a curva padrão com solução de Trolox em diferentes concentrações e suas respectivas porcentagens de descoloração. Os resultados foram expressos em $\mu \mathrm{L}$ de trolox $\mathrm{g}^{-1}$ de amostra.

\subsubsection{ABTS (2,2'-azino-bis (3-etilbenzotiazolin) 6-ácido sulfônico)}

Para a avaliação da atividade antioxidante pelo método ABTS utilizou-se o procedimento Trolox Equivalent Antioxidant Capacity (TEAC), descrito por Berg et al. (1999) e Re et al. (1999), com algumas modificações. O princípio do método do ABTS consiste no monitoramento do decaimento 
do radical ABTS, produzido pela reação de oxidação do 2,2-azinobis (3-etilbenzotiazolina-6-ácido sulfônico - ABTS), causada pela adição de amostra contendo compostos antioxidantes (CAMPOS e LISSI, 1997).

Foram preparadas soluções de Trolox (Sigma-Aldrich 238813) e dos grãos de soja com etanol. Dez microlitros de cada solução foram adicionados a $990 \mu \mathrm{L}$ de solução de ABTS. A absorbância, medida de 1 em 1 minuto até 6 minutos, foi comparada com o branco composto por $10 \mu \mathrm{L}$ de solvente (no caso, etanol adicionado a $990 \mu \mathrm{L}$ de solução ABTS). Determinou-se a redução da absorbância após 5 minutos.

Calculou-se a TEAC em relação à solução de Trolox (ARTS et al., 2004). A solução estoque de Trolox foi diluída em 4 pontos (2,5 $\mu \mathrm{M}$ (1:799); $5 \mu \mathrm{M}$ (1:399); $10 \mu \mathrm{M}$ (1:199); $15 \mu \mathrm{M}(1: 132))$ e a curva padrão preparada.

\subsubsection{Quantificação de polifenois totais, livres e ligados a proteínas}

Determinou-se o teor de polifenois totais após extração com NaOH e centrifugação por 15 minutos, com leitura em espectrofotômetro em comprimento de onda de $328 \mathrm{~nm}$. Para determinação dos polifenois livres realizou-se a extração e posterior mistura com solução de albumina bovina, seguida de precipitação de proteínas com $5 \%$ de ácido tricloroacético, centrifugação e leitura. Obteve-se o polifenol ligado por diferença (CARBONARO et al., 2000).

\subsubsection{Análise estatística}

Todas as análises foram realizadas em triplicata e os resultados obtidos submetidos à análise de variância pelo teste $\mathrm{F}$ e ao teste de Tukey $(p<0,05)$ para identificar diferenças significativas entre as médias (PIMENTEL-GOMES, 1982), utilizando-se o programa SAS (STATISTICAL ANALYSIS SYSTEM, 1996).

\section{RESULTADOS E DISCUSSÃO}

\subsection{PERFIL DE ÁCIDOS GRAXOS}

A soja contém grande quantidade de óleo rico em ácidos graxos insaturados (aproximadamente $85 \%$ do total), apresentando alto teor de ácido linoleico (49,8-59,0\%), de 20 a $27 \%$ de ácido oleico e, entre 5 e $11 \%$ de ácido linolênico (BRASIL, 2006).

Teixeira et al. (1985), estudando a variação do perfil lipídico de algumas variedades de grãos de soja brasileiros (Santa Rosa, Paraná e Davis), encontraram valores de ácido graxo palmítico que variaram de 13,88 a $26,14 \%$; oleico de 13,19 a $31,78 \%$; esteárico de 5,03 a $9,74 \%$; linoleico de 28,81 a $42,30 \%$ e de 6,35 a $20,10 \%$ para o linolênico. A Figura 1 mostra percentual semelhante dos ácidos graxos palmítico (22,50 e 24,26 \%), esteárico (5,96 e 5,24 \%), oleico (16,16 e $16,11 \%$ ) e linoleico $(50,29$ e 49,22\%) nos cultivares estudados (Embrapa 48 e BRS 213). O ácido graxo linolênico (5,07 e 5,13\%) apresentou teores similares aos encontrados por Vieira, Cabral e Paula (1999) (4,64 a 7,69 \%), quando avaliaram seis cultivares de soja destinadas à alimentação humana. Não houve diferença entre as duas variedades analisadas quanto ao teor desses ácidos graxos (Figura 1).

Tango et al. (1983) verificaram que o conteúdo de óleo de diferentes cultivares de soja e a composição em ácidos graxos variam significativamente em função do cultivar e do local de plantio. Dornbos e Mullen (1992) constataram que pode ocorrer variação dessa concentração com estresse hídrico, elevando a concentração de proteína e diminuindo a de óleo com o aumento da duração do estresse. Como os dois cultivares avaliados foram obtidos em mesma condição de cultivo e plantados em mesmo local e tempo, esses fatores não influenciaram sua composição de ácidos graxos. 




\section{FIGURA 1 - PORCENTAGEM DE ÁCIDOS GRAXOS (PALMÍTICO, ESTEÁRICO, OLEICO, LINOLEICO E LINOLÊNICO) ENCONTRADOS NOS CULTIVARES EMBRAPA 48 E BRS 213}

O processo de irradiação dos alimentos tem o propósito de estender a vida útil e reduzir perdas das safras durante o armazenamento do produto. No entanto, algumas mudanças químicas podem ser induzidas nos alimentos como resultado da utilização desse procedimento.

Após a aplicação das diferentes doses de radiação não foi possível verificar diferença significativa entre os tratamentos, embora tenha ocorrido aumento numérico na porcentagem de ácido linoleico nas doses de 4 kGy e 8 kGy (Figura 2). Ao analisar o efeito da radiação em cultivares de amendoim, Camargo et al. (2011) também verificaram aumento no teor de ácido linoleico, precursor de ácidos graxos de cadeia muito longa que atuam no desenvolvimento e funcionamento do cérebro e da retina. Portanto, o processo de irradiação nas doses empregadas não alterou as porcentagens de ácidos graxos avaliados.

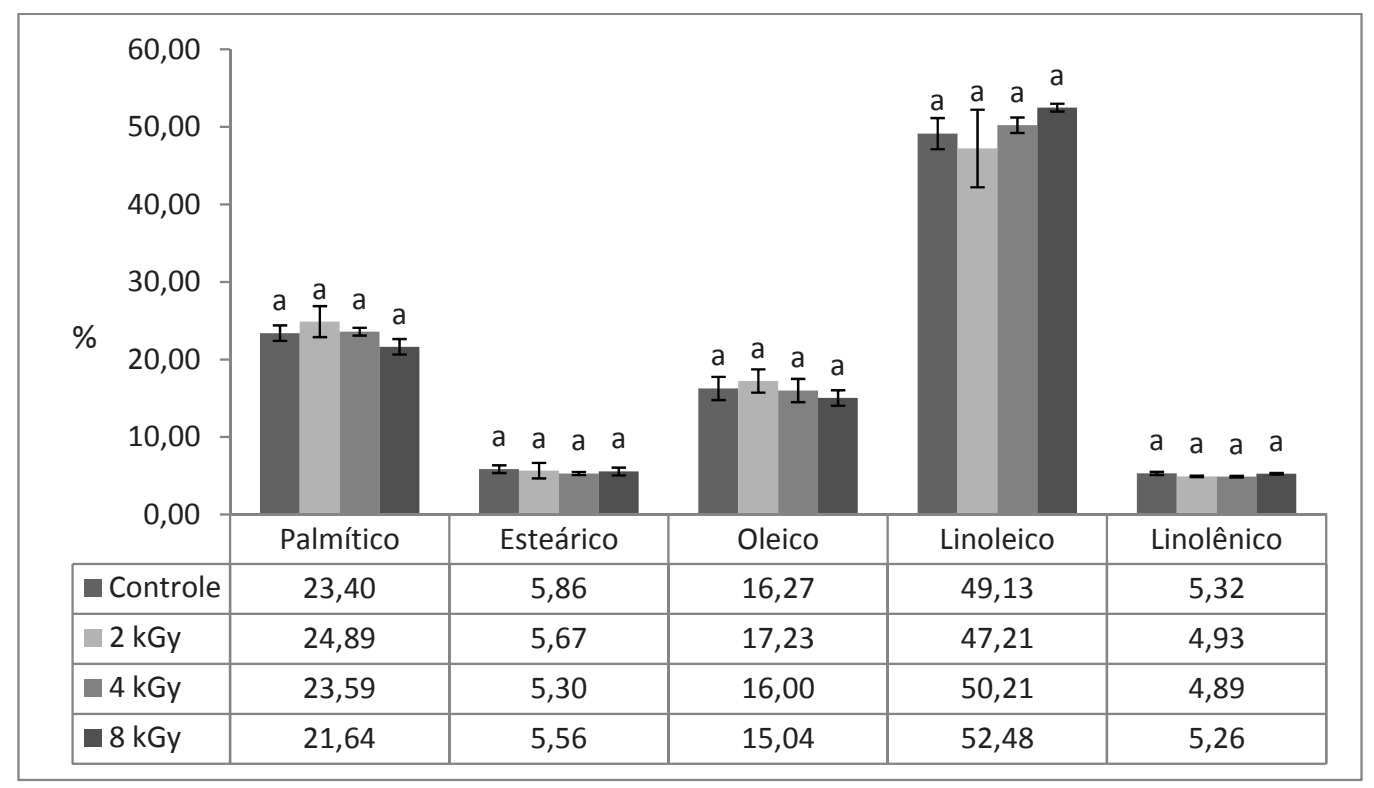

FIGURA 2 - PORCENTAGEM DE ÁCIDOS GRAXOS (PALMÍTICO, ESTEÁRICO, OLEICO, LINOLEICO E INOLÊNICO) ENCONTRADOS NO CONTROLE E NAS DOSES DE RADIAÇÃO ESTUDADAS (2, 4 E 8 kGy) 


\subsection{ISOFLAVONAS}

A análise dos resultados revelou que as concentrações ( $\mu \mathrm{g} \mathrm{g}^{-1}$ de amostra) das isoflavonas apresentaram diferenças significativas entre os cultivares, com exceção da glicitina (3478,13 e $2879,74 \mu_{g^{-1}}$ ) e daidzeína (52,77 e 52,92 $\mu \mathrm{g} \mathrm{g}^{-1}$ ) (Figura 3). Segundo Hoeck et al. (2000) e Vyn et al. (2002), a quantidade total de isoflavonas e seu perfil de distribuição variam conforme o cultivar, local de plantio, tipo de solo, clima e ano da safra. Os cultivares avaliados não sofreram influência desses fatores, pois foram obtidos sob as mesmas condições.

Apenas para a isoflavona genisteína, o cultivar BRS 213 apresentou valores superiores ao do cultivar Embrapa $48\left(540,72 \mu^{-1} g^{-1}\right)$.

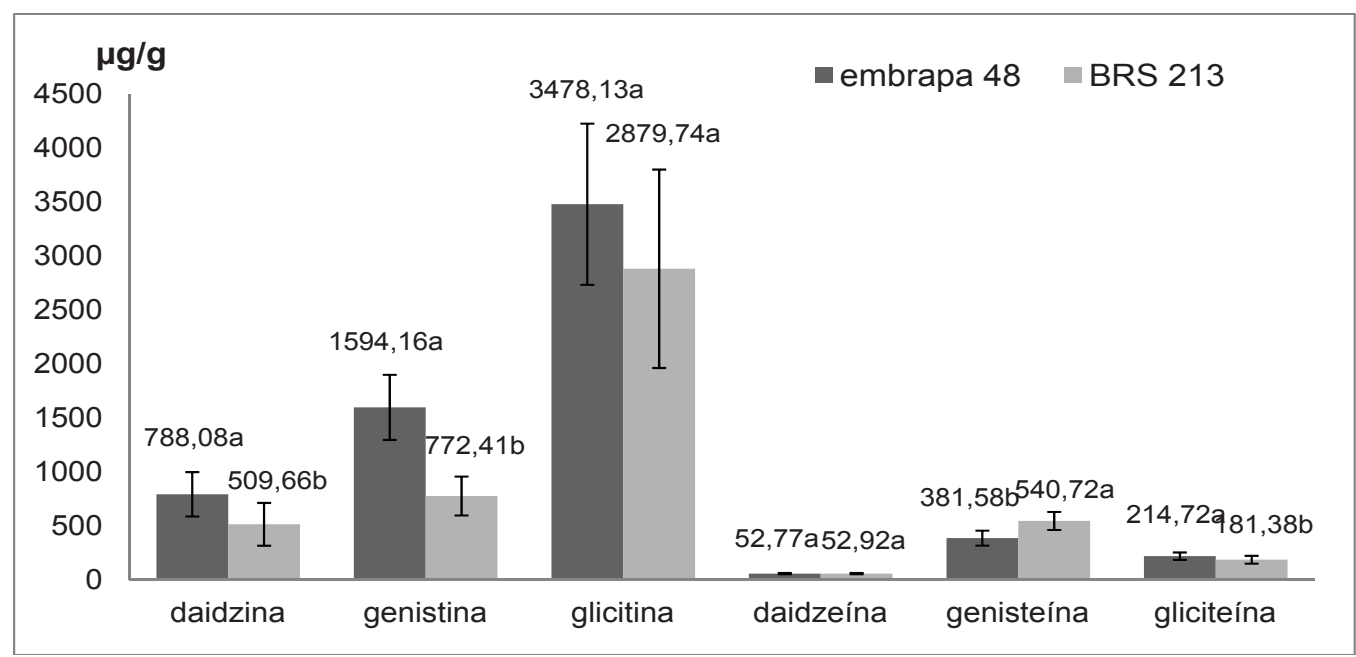

\section{FIGURA 3 - TEORES DE ISOFLAVONAS (DAIDZINA, GLICITINA, GENISTINA, DAIDZEÍNA, GLICITEÍNA E GENISTEÍNA), EM $\mu \mathrm{g} \mathrm{g}^{-1}$ DE AMOSTRA, NOS CULTIVARES EMBRAPA 48 E BRS 213}

Park et al. (2001) verificaram variações dos teores das isoflavonas daidzina (118,4 e $\left.749,4 \mu \mathrm{g} \mathrm{g}^{-1}\right)$, glicitina $\left(16,1\right.$ a 130,4 $\left.\mu \mathrm{g} \mathrm{g}^{-1}\right)$, genistina $\left(245,0\right.$ a 1286,2 $\left.\mu \mathrm{g} \mathrm{g}^{-1}\right)$, daidzeína $(5,1$ a $\left.59,3 \mu \mathrm{g} \mathrm{g}^{-1}\right)$ e genisteína $\left(13,9\right.$ a $\left.60,4 \mu \mathrm{g} \mathrm{g}^{-1}\right)$ entre diferentes cultivares de soja procedentes da mesma região brasileira. Comparando os resultados encontrados pelos autores com os do presente trabalho constatou-se que somente as isoflavonas daidzina e daidzeína apresentaram valores semelhantes. Para as demais isoflavonas, os dois cultivares estudados apresentaram teores bem maiores que os descritos por aqueles autores, devido inúmeros fatores que podem alterar a quantidade de isoflavonas nos grãos (HOECK et al., 2000 e VYN et al., 2002).

Góes-Favoni et al. (2004) verificaram que os teores de malonil-glicosídeos em dois tipos de farinha cozidas $\left(77,8\right.$ e $\left.81,5 \mu \mathrm{g} \mathrm{g}^{-1}\right)$ mostraram-se menores que os encontrados na farinha crua (147,7 $\mathrm{\mu g} \mathrm{g}^{-1}$ ), enquanto o teor de agliconas (daidzeína, gliciteína e genisteína) e de glicosídeos foi maior. As frações malonil-glicosil isoflavonas são termolábeis e se convertem em suas glicosilisoflavonas quando expostas a altas temperaturas (KUDOU et al., 1991). Como todos os grãos do presente estudo foram cozidos é provável que tenha havido tal transformação.

Aguiar (2004) estudou diferentes cultivares de soja brasileiros e verificou que o extrato metanólico de grão tratado por radiação gama apresentou perda gradual no conteúdo de isoflavonas totais (perda de 33,5\%).

No presente estudo, não foi possível observar diferenças significativas entre os valores de isoflavonas após a utilização das diferentes doses de irradiação (Figura 4). Os resultados corroboram o estudo de Yun et al. (2012) em que não foram observadas alterações significativas nos teores de isoflavonas de sojas tratadas com 0, 1, 3, 5 e 10 kGy de radiação gama. 


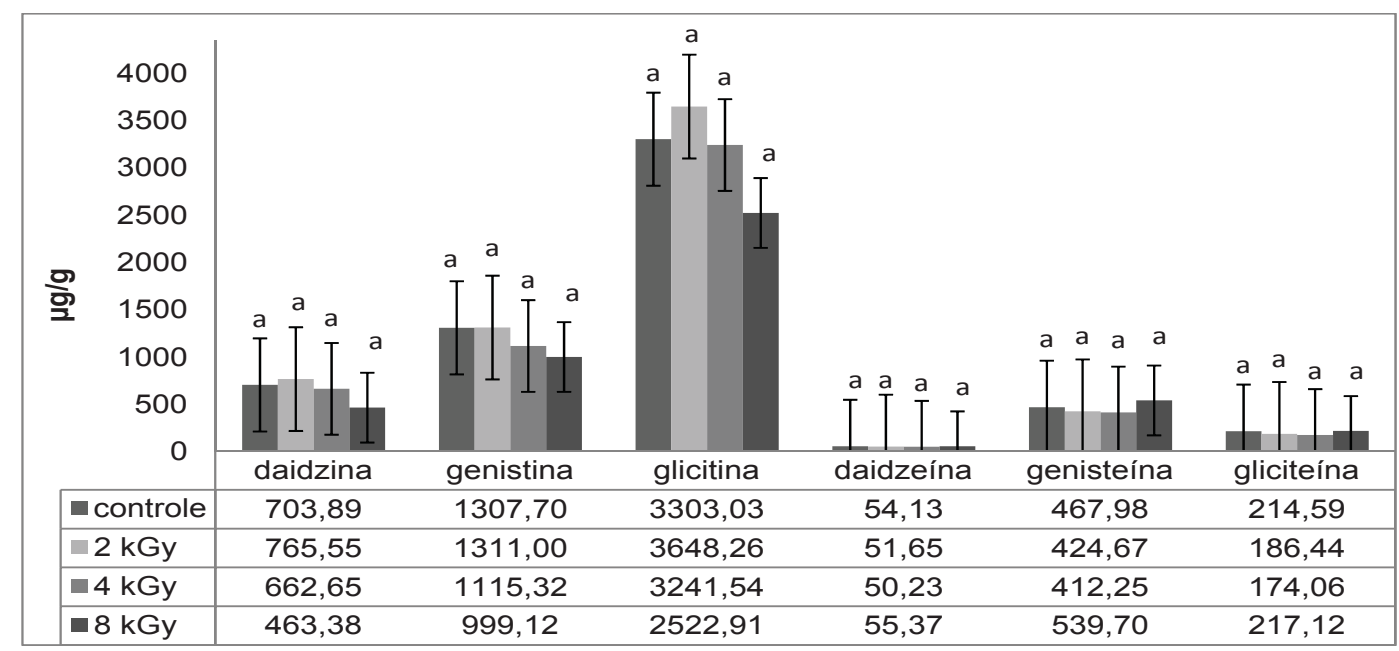

\section{FIGURA 4 - TEORES DE ISOFLAVONAS (DAIDZINA, GLICITINA, GENISTINA, DAIDZEÍNA, GLICITEÍNA E GENISTEÍNA), EM $\mu \mathrm{g} \mathrm{g}^{-1}$ DE AMOSTRA, PARA AS DOSES DE RADIAÇÃO 0, 2, 4 e 8 kGy}

\subsection{CAPACIDADE ANTIOXIDANTE}

Conforme a Tabela 1, a atividade antioxidante apresentou resultados estatisticamente semelhantes entre os cultivares estudados por ambos os métodos utilizados. Contrariamente aos resultados encontrados, Sapbamrer, Pinta e Tantipaiboonwong (2012) observaram diferenças significativas quanto a atividade antioxidante (\% DPPH) de cultivares de soja de diferentes regiões da Tailândia. Os cultivares da região norte apresentaram atividade antioxidante média de 25,72 \%, enquanto os da região central do país mostraram $14,07 \%$, sugerindo que a atividade antioxidante sofre influência de fatores genéticos, localização geográfica e ambiental, tais como temperatura, precipitação, fertilidade do solo e luminosidade. $O$ fato dos cultivares estudados serem provenientes da mesma região geográfica e ambiental pode explicar a semelhança entre os resultados.

\section{TABELA 1 - ATIVIDADE ANTIOXIDANTE DOS DOIS CULTIVARES, OBTIDA POR DPPH (\%) E ABTS (\%)}

\begin{tabular}{c|c|c}
\hline & Embrapa 48 & BRS 213 \\
\hline DPPH & $78,66 \pm 2,8^{1 \mathrm{a} 2}$ & $76,77 \pm 2,4^{\mathrm{a}}$ \\
ABTS & $4,47 \pm 2,9^{\mathrm{a}}$ & $3,45 \pm 3,3^{\mathrm{a}}$ \\
\hline
\end{tabular}

${ }^{1}$ Média \pm desvio padrão. ${ }^{2}$ Médias com letra(s) diferente(s) na horizontal diferem significativamente em nível de $\mathrm{p} \leq 0,05$.

Os resultados da atividade antioxidante, com relação às diferentes doses estudadas, estão apresentados na Tabela 2.

TABELA 2 - ATIVIDADE ANTIOXIDANTE PARA AS DOSES DE RADIAÇÃO (0, 2, 4 e 8 kGy), OBTIDA PELOS MÉTODOS DPPH (\%) e ABTS (\%)

\begin{tabular}{ccccc}
\hline \multicolumn{5}{c}{ Doses de radiação (kGy) } \\
\hline Controle & $\mathbf{2}$ & $\mathbf{4}$ & $\mathbf{8}$ \\
\hline DPPH & $76,90 \pm 1,7^{1 \mathrm{bc} 2}$ & $82,71 \pm 0,3^{\mathrm{a}}$ & $79,31 \pm 0,4^{\mathrm{b}}$ & $75,73 \pm 1,1^{\mathrm{c}}$ \\
ABTS & $1,67 \pm 0,6^{\mathrm{a}}$ & $3,56 \pm 1,2^{\mathrm{a}}$ & $6,18 \pm 2,1^{\mathrm{a}}$ & $6,48 \pm 3,7^{\mathrm{a}}$ \\
\hline
\end{tabular}

\footnotetext{
${ }^{1}$ Média \pm desvio padrão. ${ }^{2}$ Letra(s) diferente(s) na horizontal diferem significativamente em nível de $p \leq 0,05$.
} 
A atividade antioxidante obtida por DPPH apresentou diferença significativa entre as amostras irradiadas com 2 e 4 kGy em relação ao controle e a irradiação com 8 kGy. As amostras irradiadas com doses menores mostraram maior capacidade antioxidante pela metodologia DPPH, sugerindo estabilidade da capacidade antioxidante a partir de determinadas doses de irradiação.

Variyar, Limayer e Sharma (2004) observaram aumento na porcentagem da capacidade antioxidante nas doses de 0,5 a $5 \mathrm{kGy}$, também utilizando a metodologia de DPPH e padrão Trolox. Segundo tais autores, o aumento das isoflavonas livres com a utilização de radiação acima de 1 kGy pode explicar o incremento da capacidade antioxidante das amostras.

As amostras irradiadas com 4 e $8 \mathrm{kGy}$ e analisadas pelo método ABTS apresentaram capacidade antioxidante maior que o controle, podendo ter ocorrido a liberação de compostos antioxidantes.

A diferença entre os resultados encontrados entre os métodos ABTS e DPPH pode ser justificada pelas características e mecanismo de ação dos compostos bioativos, além da metodologia utilizada para avaliar a sua propriedade antioxidante (MELO et al., 2006).

Nas Tabelas 3 e 4 estão apresentadas as atividades antioxidantes das amostras nas diferentes doses de irradiação, medidas por DPPH e ABTS.

TABELA 3 - ATIVIDADE ANTIOXIDANTE NOS GRÃOS DO CULTIVAR EMBRAPA 48 SUBMETIDOS À IRRADIAÇÃO (0, 2, 4 E 8 kGy), OBTIDA POR DPPH (\%) E ABTS (\%)

\begin{tabular}{ccccc}
\hline \multicolumn{5}{c}{ Doses de radiação $(\mathbf{k G y})$} \\
\hline Controle & $\mathbf{2}$ & $\mathbf{4}$ & $\mathbf{8}$ \\
ABPH & $76,90 \pm 1,7^{1 \mathrm{bc} 2}$ & $82,71 \pm 0,3^{\mathrm{a}}$ & $79,31 \pm 0,4^{\mathrm{b}}$ & $75,73 \pm 1,1^{\mathrm{c}}$ \\
\hline
\end{tabular}

${ }^{1}$ Média \pm desvio padrão. ${ }^{2}$ Letra(s) diferente(s) na horizontal diferem significativamente em nível de $p \leq 0,05$.

Os resultados experimentais revelaram que o cultivar Embrapa 48 apresentou aumento na atividade antioxidante (DPPH) com a dose de $2 \mathrm{kGy}$, enquanto as amostras irradiadas com 4 e 8 kGy não diferiram do controle (Tabela 3).

Pelo método ABTS não houve diferença significativa entre o controle e as amostras irradiadas.

TABELA 4 - ATIVIDADE ANTIOXIDANTE NOS GRÃOS DO CULTIVAR BRS 213 SUBMETIDOS À IRRADIAÇÃO (0, 2, 4 E 8 kGy), OBTIDA POR DPPH (\%) E ABTS (\%)

\begin{tabular}{ccccc}
\hline \multicolumn{5}{c}{ Doses de radiação (kGy) } \\
\hline CPPH & Controle & $\mathbf{2}$ & $\mathbf{4}$ & $\mathbf{8}$ \\
\multirow{2}{*}{ ABTS } & $76,90 \pm 1,7^{1 \mathrm{bc} 2}$ & $82,71 \pm 0,3^{\mathrm{a}}$ & $79,31 \pm 0,4^{\mathrm{b}}$ & $75,73 \pm 1,1^{\mathrm{c}}$ \\
\hline
\end{tabular}

${ }^{1}$ Média \pm desvio padrão. ${ }^{2}$ Letra(s) diferente(s) na horizontal diferem significativamente em nível de $p \leq 0,05$.

Conforme a Tabela 4 é possível observar que o controle e as amostras irradiadas com 8 kGy não apresentaram diferenças significativas entre os resultados obtidos por ambos os métodos.

As amostras irradiadas com 2 e 4 kGy apresentaram maior capacidade de oxidação com a utilização do método DPPH, sugerindo estabilidade da capacidade antioxidante a partir de determinadas doses de irradiação. Já com relação ao método ABTS, as amostras irradiadas com 
2 kGy apresentaram a menor capacidade antioxidante.

Khattak et al. (2008), estudando a semente de Nigella sativa, afirmaram que a atividade antioxidante (medida por DPPH) das amostras extraídas, tanto com metanol como com acetona, aumenta com doses crescentes de irradiação (de 2 a $16 \mathrm{kGy}$ ), concordando com o resultado encontrado (Tabela 4).

\subsection{COMPLEXAÇÃO POLIFENOIS-PROTEÍNAS}

As sementes de soja contêm mais proteínas que qualquer outra cultura comercial. Aproximadamente $41 \%$ (em termos de massa seca) da semente de soja consiste em proteínas de armazenamento e $21 \%$ em óleo (YAKLICH, 2001). No entanto, os grãos de leguminosas apresentam fatores antinutricionais que podem provocar efeitos fisiológicos adversos ou diminuir a biodisponibilidade de nutrientes (SILVA e SILVA, 1999).

Taninos são compostos fenólicos considerados antinutrientes devido seu efeito adverso na digestibilidade da proteína (BENEVIDES et al., 2011), já que contém grupos hidroxilas fenólicas suficientes para permitir a formação de ligações cruzadas estáveis com proteínas (DESHPANDE, CHERYAN e SALUNKE, 1986).

Os resultados experimentais mostraram que o cultivar BRS 213 apresentou teor de polifenois totais superior (2,70 \%) ao cultivar Embrapa 48 (2,31\%), diferindo significativamente entre si (Figura 5).

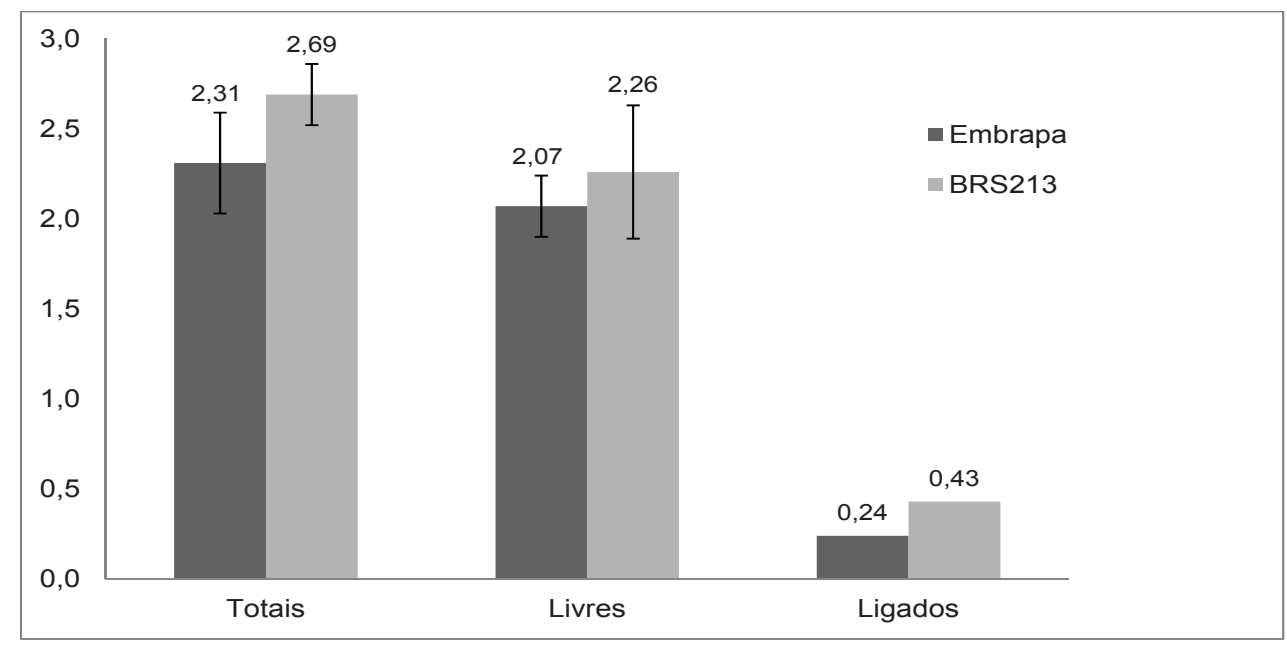

\section{FIGURA 5 - QUANTIDADE DE POLIFENOIS TOTAIS, LIVRES E LIGADOS PARA OS DOIS CULTIVARES ESTUDADOS (EMBRAPA 48 E BRS 213)}

O resultado dos polifenois totais, livres e ligados para as diferentes doses de radiação estudadas (0, 2, 4 e 8 kGy) constam na Figura 6.

O estudo não revelou alterações nos teores de polifenois totais nas amostras, entretanto, as doses de 2 e 8 kGy proporcionaram aumento significativo nos valores de polifenois livres em relação ao grupo controle. Esse resultado pode ser explicado pelos grupos sulfidrilas livres das proteínas serem sensíveis à irradiação (GROLICHOVÁ et al., 2004). Tal fato pode causar redução das ligações dissulfeto e/ou oxidação dos grupos sulfidrilas (SOUZA e NETTO, 2006), liberando essas proteínas de sua complexação com os polifenois. Nesse caso, o aumento de polifenois livres ocasionado pela irradiação é benéfico, já que disponibiliza a proteína anteriormente ligada. Os resultados de complexação são importantes porque a ligação com as proteínas provoca mudanças, tanto na conformação das proteínas quanto na conformação dos taninos, resultando em insolubilidade do complexo formado (ASQUITH e BUTLER, 1986). 


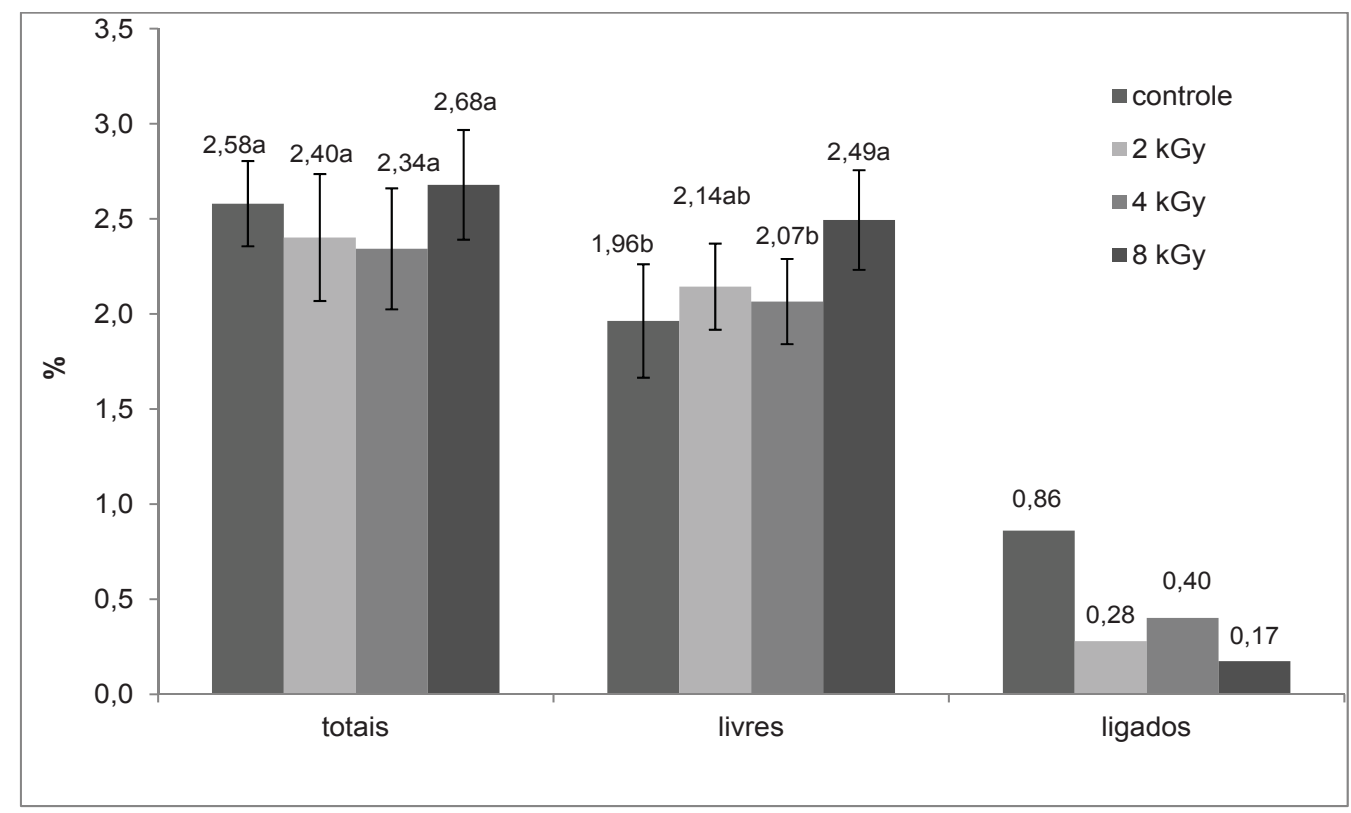

\section{FIGURA 6 - QUANTIDADE DE POLIFENOIS TOTAIS, LIVRES E LIGADOS PARA AS QUATRO DOSES DE RADIAÇÃO UTILIZADAS (0, 2, 4 e 8 kGy)}

\section{CONCLUSÃO}

A irradiação nas doses utilizadas nos dois cultivares promoveu redução nas quantidades de ácidos linolênico e linoleico, mas o perfil lipídico permaneceu semelhante. Com relação às isoflavonas, o tratamento de radiação provocou aumento nos seus teores na dose de $2 \mathrm{kGy} e$ diminuição com a utilização de 4 e 8 kGy. A irradiação também foi responsável pelo aumento da capacidade antioxidante e redução da complexação entre os polifenois e as proteínas. A partir desses resultados pode-se concluir que a radiação gama não alterou significativamente as características químicas dos cultivares de soja estudados. No entanto, novas pesquisas justificam-se para avaliar se a irradiação nas doses utilizadas constitui método eficaz para o aumento da vida útil do produto.

\section{ABSTRACT \\ EFFECTS OF THE GAMMA RADIATION IN NUTRITIONAL QUALITY OF SOYBEAN GRAINS Glycine $\max (\mathrm{L}$.}

The objective of this study was to determine alterations caused by gamma radiation (doses of 0, 2, 4 and 8 kGy) in two different soybean cultivars (BRS 213 and Embrapa 48). The study included analysis of the lipid profile, isoflavones and total, free and protein-binding polyphenols. Both cultivars showed similar lipid profile and the irradiation decreased the amount of linoleic and linolenic acids. The results showed that glycosylated isoflavones were increased at $2 \mathrm{kGy}$ and decreased at 4 and $8 \mathrm{kGy}$ of radiation. The radiation was also responsible for the increase of antioxidant activity and for protein-binding polyphenols reduction. The results of this study indicated that gamma radiation did not change significantly the chemical characteristics of the soybean cultivars.

KEY-WORDS: SOYBEANS; GAMMA RADIATION; ISOFLAVONES; LIPID PROFILE; ANTIOXIDANT ACTIVITY.

\section{REFERÊNCIAS}

1 AGUIAR, C.L. Transformação física e bioquímica de isoflavonas conjugadas de soja (Glycine max L.) e o efeito na atividade biologica in vitro. 2004. 285 f. Dissertação. (Doutorado em Ciências de Alimentos), Faculdade de Engenharia de Alimentos, Universidade Estadual de Campinas, Campinas, 2004

2 ABDILLE, M.D.H.; SINGH, R.P.; JAYAPRAKASHA, G.K.; JENA, B.S Antioxindant activity of the extracts from Dillenia indica fruits. Food Chemistry, Barking, v.90, n.4, p.891-896, 2005. 
3 ARTS, M.J.T.J.; DALLINGA, J.S.; VONS, H.P.; HAENEN, G.R.M.M.; BAST, A. A new approach to assess the total antioxidant capacity using the TEAC assay. Food Chemistry, London, v.88, n.4, p.567-570, 2004.

4 Associação Brasileira das Indústrias de Óleos Vegetais (ABIOVE). Importância econômica e social. Disponível em: < http://www.abiove.org.br/site/index.php> Acesso em: 26 de fevereiro de 2013.

5 ASQUITH, T.N.; BUTLER, L.G. Interactions of condensed tannins with selected proteins. Phytochemistry, Oxford, v.25, n.7, p.1591-1593, 1986.

6 BARNES, S.; KIRK, M.; COWARD, L. Isoflavones and their conjugates in soy foods: extraction conditions and analysis by HPLC-mass spectrometry. Journal of Agricultural and Food Chemistry, v.42, p.2466-2474, 1994.

7 BENEVIDES, C.M.J. et al. Fatores antinutricionais em alimentos: revisão. Segurança Alimentar e Nutricional, v.18, n.2, p.67-79, 2011.

8 BERG, V.D. et al. Applicability of an improved Trolox equivalent antioxidant capacity (TEAC) assay for evaluation of antioxidant capacity measurements of mixtures. Food Chemistry, v.66, n.4, p.511-517, 1999.

9 BLIGH, E.G.; DYER, W.J. A rapid method for total lipid extraction and purification. Canadian Journal of Biochemistry and Physiology, v.37, p.911-917, 1959.

10 BRAND-WILLIAMS, W.; CUVIER, M.E.; BERSET, C. Use of a free radical method to evaluate antioxidant activity. Lebensmittel-Wissenschaft und Technologie, v.28, p.25-30, 1995.

11 BRASIL. Ministério da Agricultura, Pecuária e Abastecimento. Instrução Normativa n 49, de 22 de dezembro de 2006. Aprova o regulamento técnico de identidade e qualidade dos óleos vegetais refinados; a amostragem; os procedimentos complementares; e o roteiro de classificação de óleos vegetais refinados. Diário Oficial [da] República Federativa do Brasil, Brasília, DF, 26 dez. 2006. Seção 1, p.140.

12 CAI, T.; CHANG, K.C. Processing effect on soybean storage proteins and their relationship with tofu quality. Journal of Agricultural and Food Chemistry, v.47, n.2, p.720-727, 1999

13 CAMARGO, A.C. et al. Efeitos da radiação gama na cor, capacidade antioxidante e perfil de ácidos graxos em amendoim (Arachis hypogaea L.). Ciência e Tecnologia de Alimentos, v.31, n.1, p.11-15, jan./mar. 2011.

14 CAMPOS, A.M.; LISSI, E.A. Kinetics of the reaction between 2,2-azinobis(3- ethylbenzothiazoline-6-sulfonic acid) (ABTS) derived radical cations and phenols. International Journal of Chemical Kinetics, v.29, n.3, p.219-224, 1997.

15 CARBONARO, M. et al. Perspectives into factors limiting in vivo digestion of legume proteins: antinutritional compounds or storage proteins. Journal of Agricultural and Food Chemistry, v.48, p.742-749, 2000.

16 Companhia Nacional de Abastecimento (CONAB). Estimativa da produção de grãos: safra 2012/2013. Brasília, DF. Disponível em: http://www.conab.gov.br/OlalaCMS/uploads/arquivos/13_02_08_17_24_51_boletim_fevereiro_2013.pdf Acesso em: 26 de fevereiro de 2013.

17 COWARD, L.; SMITH, M.; KIRK, M.; BARNES, S. Chemical modification of isoflavones in soyfoods during cooking and processing. American Journal of Clinical Nutrition, v.68, p.1486-1491S, 1998.

18 DESHPANDE, S.S.; CHERYAN, M.; SALUNKHE, D.K. Tannin analysis of food products. CRC Critical Reviews in Food Science and Nutrition, v.24, n.4, p.401-449, 1986.

19 DIEHL, J.F. Food irradiation: past, present and future. Radiation Physics and Chemistry, v.63, n.3-6, p.211-215, 2002.

20 DORNBOS, D.L.; MULLEN, R.E. Soybean seed protein and oil contents and fatty acid composition adjustment by drought and temperature. Journal of American Oil Chemists Society, v.69, p.228- 231, 1992.

21 Empresa Brasileira de Pesquisa Agropecuária (EMBRAPA AGROSSILVIPASTORIL). Perdas de grãos no pós-colheita são discutidas em workshop em Sinop. Disponível em: http://cpamt.sede.embrapa.br/ imprensa/noticias/perdas-degraos-no-pos-colheita-sao-discutidos-em-workshop-em sinop/?searchterm=perdas\%20de\%20soja Acesso em: 26 de fevereiro de 2013.

22 ESAKI, H.; WATANABE, R.; ONOZAKI, H.; KAWAKISHI, S.; OSAWA, T. Formation mechanism for potent antioxadative O-dihydroxy-isoflavones in soybean fermented with Aspergillus saitoi. Bioscience, Biotechnology, Biochemistry, v.63, n.5, p.851-858, 1999.

23 FUKUTAKE, M.; TAKAHASHI, M.; ISHIDA, K.; KAWAMURA, H.; SUGIMURA, T.; WAKABAYASHI, K. Quantification of genistein and genistin in soybeans and soybean products. Food and Chemical Toxicology, v.34, n.5, p.457-461, 1996.

24 GÓES-FAVONI, S.P. et al. Isoflavonas em produtos comerciais de soja. Ciência e Tecnologia de Alimentos, v.24, n.4, p.582-586, 2004

25 GROLICHOVÁ, M. et al. Employing ionizing radiation to enhance food safety - a review. Acta Veterinaria Brunensis, 
v.73, n.1, p.143-149, 2004.

26 HARTMAN, L.; LAGO, R.C.A. Rapid preparation of fatty acid methyl esters from lipids. Laboratory Practice, v. 22, p.475-494, 1973.

27 HOECK, J.A. et al. Influence of genotype and environment contents of soybean. Crop Science, v.40, p.48-51, 2000.

$28 \mathrm{HOU}, \mathrm{H} . J . ;$ CHANG, K.C. Yield and textural properties of tofu as affected by the changes of phytate content during soybean storage. Journal of Food Science, v.68, n.4, p.1185-1191, 2003.

29 HOU, D.H.J.; CHANG, K.C. Structural characteristics of purified glycinin from soybeans stored under various conditions. Journal of Agricultural and Food Chemistry, v. 52, n. 12, p. 3792-3800, 2004

30 HUANG, D.J.; OU, B.X.; PRIOR, R.L. The chemistry behind antioxidant capacity assays. Journal of Agricultural and Food Chemistry, v.53, n.6, p.1841-1856, 2005.

31 KHATTAK et al. Effect of gamma irradiation on the extraction yield, total phenolic content and free radical-scavenging activity of Nigella sativa seed. Food Chemistry, v.100, n.4, p.967-972, 2008.

32 KAUR, M.; SINGH, N. Characterization of protein isolates from different Indian chickpea (Cicer arietinum L.) cultivars. Food Chemistry, v.102, n.1, p.366-374, 2007.

33 KUDOU, S.; FLEURY, Y.; WELTI, D.; MAGNOLATO, D.; UCHIDA, T.; KITAMURA, K.; OKOTUBO, K. Malonyl isoflavone glycosides in soybean seeds (Glycine max Merrill). Agriculture Biologic Chemistry, v.55, n.9, p.2227-2233, 1991.

34 MELO, E. de A.; MACIEL, M.I.S.; LIMA, V.L.A.G.; LEAL, F.L.L.; CAETANO, A.C. da S.; NASCIMENTO, R.J. Capacidade antioxidante de hortaliças usualmente consumidas. Ciência e Tecnologia de Alimentos, v.26, n.3, p.639-644, 2006.

35 NOVELLI, V.M.; FREITAS-ASTÚA, J.; SEGATTI, N.; MINEIRO, J.L.C.; ARTHUR, V.; BASTIANEL, M.; HILF, M.E.; GOTTWALD, T.R.; MACHADO, M.A. Effects of radiation (Cobalt-60) on the elimination of Brevipalpus phoenicis (Acari: Tenuipalpidae) Cardinium endosymbiont. Experimental and Applied Acarology, v.45, p.147-153, 2008

36 PARK, Y.K.; AGUIAR, C.L.; ALENCAR, S.M.; SCAMPARINI, A.R.P. Avaliação do teor de isoflavonas em soja brasileira. Ciência e Tecnologia de Alimentos, v.3, n.3, p.156-160, 2001.

37 PIMENTEL-GOMES, F. Curso de estatística experimental. 10. ed. São Paulo: Editora Nobel, 1982.430 p.

38 PRIOR, R.L.; WU, X.L.; SCHAICH, K. Standardized methods for the determination of antioxidant capacity and phenolics in food and dietary supplements. Journal of Agricultural and Food Chemistry, v.53, n.10, p.4290-4302, 2005.

39 RATNAYAKE, W.M.N.; HOLLYWOOD, R.; O'GRADY, E.; BEARE-ROGERS, J.L. Determination of cis and transoctadecenoic acids in margarines by gas chromatography-infrared spectrophotometry. Journal of American Oil Chemistry Society, v.67, n.11, p.804-810, 1990.

40 RE, R.; PELLEGRINI, N.; PROTEGGENTE, A.; PANNALA, A.; YANG, M.; RICE-EVANS, C. Antioxidant activity applying an improved ABTS radical cation decolorization assay. Free Radical Biology and Medicine, v.26, n.9-10, p.1231-1237, 1999.

41 SAPBAMRER, R.; PINTA, K; TANTIPAIBOONWONG, P. Isoflavones and anti-oxidant activities of soybean in Thailand. Research Journal of Phitochemistry, v.6. n.4, p.113-119, 2012.

42 SILVA, M.R.; SILVA, M.A.A.P. Aspectos nutricionais de fitatos. Revista de Nutrição, v.12, n.1, p.5-19, 1999.

43 SINGH, R.P.; MURTH, K.N.C.; JAYAPRAKASHA, G.K. Studies on the antioxidant activity of pomegranate (Punica granatum) peel and seed extracts using in vitro models. Journal of Agricultural and Food Chemistry, v.50, n.1, p.81$86,2002$.

44 SOUZA, A.S.; NETTO, F.M. Influência da irradiação e do armazenamento nas características estruturais da proteína de soja. Brazilian Journal Food Technology, v.9, p.36-43, 2006.

45 Statistical Analysis System Institute (SAS). Sas/Qc software: usage and reference (version 6). $2^{\text {nd }}$ ed. Cary, 1996. 1 CDROM.

46 TANGO, J.S.; TURATTI, J.M.; SILVA, M.T.C.; SHIROSE, I.; YOTSUYANAGI, K. Influência do local de plantio no teor e características do óleo de algumas cultivares de soja. Boletim do Instituto de Tecnologia de Alimentos, v.20, n.4, p.355-374, 1983.

47 TEIXEIRA, J.P.F.; RAMOS; M.T.B.; MORAES; R.M.; FARACO, M.H.; MASCARENHAS, H.A.A. Acúmulo de substâncias de reserva em grãos de soja: matéria seca, óleo e ácidos graxos. Bragantia, v.44, n.1, p.295-309, 1985.

48 VARIYAR, P.S.; LIMAYER, A.; SHARMA, A. Radiation-induced enhanced of antioxidant contents of soybean (Glycine max. Merril). Journal of Agricultural and Food Chemistry, v.52, n.11, p.3385-3388, 2004. 
49 VIEIRA, C.R.; CABRAL, L.C.; PAULA, A.C.R. Composição centesimal e conteúdo de aminoácidos, ácidos graxos e minerais de seis cultivares de soja destinadas à alimentação humana. Pesquisa Agropecuária Brasileira, v.34, n.7, p.1277-1283, jul. 1999

50 VYN, T.J.; YIN, X; BRUULSEMA, T.W.; JACKSON, C.J.; RAJCAN, I.; BROUDER S.M. Potassium fertilization effects on isoflavone concentration in souybean (Glycine $\max$ (L.) Merr.). Journal of Agricultural and Food Chemistry, v.50, n.12, p.3501-3506, 2002.

51 YAKLICH, R.W. $\beta$-conglycinin and glycinin in high-protein soybean seeds. Journal of Agricultural and Food Chemistry, v.49, p.729-735, 2001.

52 YUN, J.; LI, X.; FAN, X; TANG, Y; XIAO, Y; WAN, S. Effect of gamma irradiation on microbial load, physicochemical and sensory characteristics of soybeans (Glycine max L. Merrill). Radiation Physics and Chemistry, v.81, n.8, p.1198-1202, 2012

\section{AGRADECIMENTOS}

À FAPESP pelo auxílio financeiro e à EMBRAPA pela doação dos grãos. 